\title{
Experimental and Analytical Investigation of Deformations and Stress Distribution in Steel Bands of a Two-Span Stress-Ribbon Pedestrian Bridge
}

\author{
G. Sandovic, ${ }^{1}$ A. Juozapaitis, ${ }^{1}$ and V. Gribniak ${ }^{2}$ \\ ${ }^{1}$ Department of Bridges and Special Structures, Vilnius Gediminas Technical University (VGTU), LT-10223 Vilnius, Lithuania \\ ${ }^{2}$ Research Laboratory of Innovative Building Structures, VGTU, LT-10223 Vilnius, Lithuania \\ Correspondence should be addressed to V. Gribniak; viktor.gribniak@vgtu.lt
}

Received 1 February 2017; Revised 9 April 2017; Accepted 30 April 2017; Published 29 May 2017

Academic Editor: Fabrizio Greco

Copyright (C) 2017 G. Sandovic et al. This is an open access article distributed under the Creative Commons Attribution License, which permits unrestricted use, distribution, and reproduction in any medium, provided the original work is properly cited.

\begin{abstract}
The article is dedicated to the analysis of problems related to design of pedestrian bridges with flexible ribbon bands made of steel. The study is based on test results of a bridge model that has two spans (each with a length of five meters). A simplified analytical technique has been proposed for predicting vertical deformations of the bridge structure subjected to symmetrical or asymmetrical loading patterns. The technique also allows assessing the tension forces in the ribbons, which are very important for design of such structures. The analysis reveals the importance of the flexural rigidity of the ribbons that might cause significant redistribution of stresses within the steel bands.
\end{abstract}

\section{Introduction}

Monumental engineering structures, particularly bridges, are omnipresent in every society, regardless of culture, religion, geographical location, and economic development $[1,2]$. The stress-ribbon structural scheme can be considered as one of the most efficient for pedestrian bridges [3-5]. A deck (often prestressed concrete slabs) with a catenary shape forms the stress-ribbon structure. The load-bearing structure consists of slightly sagging cables (tensioned bands), bedded in a thin slab. The traffic is often placed directly on the slab embedding the cables. Compared with other structural types, the stressribbon system can be considered extremely simple though requiring massive anchorage blocks due to very large tensile stresses induced in the cables. The smooth curved shape of the bridge is well tailored to the environment: the height of the bridge girder is the smallest among all known bridge types $[1,3]$. Three common structural schemes exist for the stressribbon bridges $[1,3,6-8]$ : prefabricated concrete slabs suspended on steel cables, prestressed concrete structures, and steel band systems. Due to the specific static and dynamic characteristics, these constructions are mainly used for pedestrian and bicycle traffic $[3,7,8]$.
Stress-ribbon bridges are often constructed by using a multispan layout that is a consequence of exploitation conditions $[1,3,6]$. To avoid stress concentrations, connection joints of the ribbons are constructed as flexible hinges $[1,8,9]$. The structural behaviour of such bridges, however, is complicated due to the movement (horizontal displacement) of intermediate supports under traffic load $[10,11]$. An ideally flexible ribbon is also just a theoretical assumption $[12,13]$. To ensure the adequacy of analytical predictions, these nonlinear effects must be included into mathematical models $[9,10,14]$.

The first experimental studies of stress-ribbon bridge models were carried out in the Czech Republic and Germany $[3,7,14-16]$. In this context, a scaled model of a combined (supported arch) bridge over Radbuza river (Czech Republic) should be mentioned. The model (scale 1:10, span length $10.35 \mathrm{~m}$ ) was constructed by using a steel pipe as a bearing component [14]. A multispan prestressed concrete bridge model was also tested in the Czech Republic [3]. The first bridge with ribbons made of carbon fibre reinforced polymer sheets was constructed in TU Berlin (Germany) in 2007. It had $13 \mathrm{~m}$ span [16].

Notwithstanding the current experimental and analytical studies, the behaviour of bridges with ribbons made of steel 


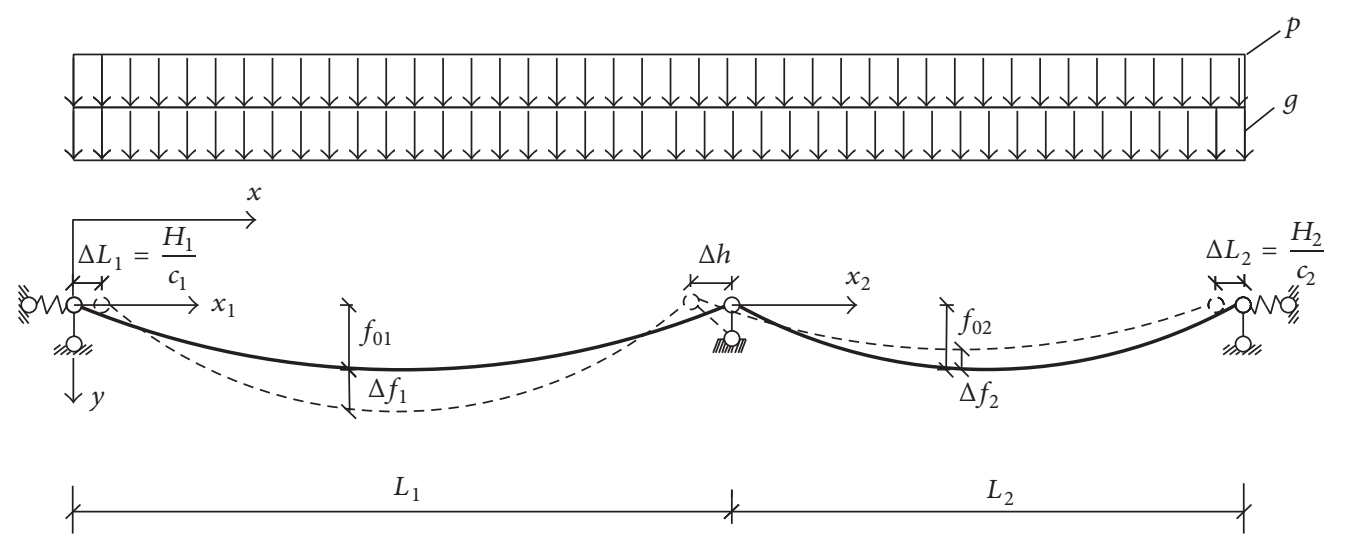

FIGURE 1: The calculation scheme of the stress-ribbon system subjected to symmetrical loading.

bands has not been fully explored [7]. The lack of clarity is mainly related to the absence of experimental studies related to the structural behaviour of multispan bridges of such structure. Besides, the frequently neglected flexural stiffness of the ribbons might be important to ensure adequate assessment of the stress distribution [12]. Therefore, the current research is dedicated to the deformation analysis of a twospan pedestrian bridge with flexible steel ribbon bands and a total length of $10 \mathrm{~m}$. A simplified analytical technique is proposed for predicting vertical deformations of the bridge structure subjected to symmetrical and asymmetrical loads. To simplify the iterative calculations, the elastic and kinematic deformation components are separated. The predictions are validated against test data of the bridge.

\section{Analytical Technique for Deformation Analysis of the Two-Span Bridge}

2.1. Assumptions. The ribbon bands are the main components of the considered bridge. The deformation state of the ribbon bands is described by kinematic and elastic components. The behaviour of the ribbon is assumed to be geometrically nonlinear. The flexural stiffness of the band is completely neglected (i.e., $E I=0$ ). A second-order parabolic shape describes the deformations of the strip subjected to the dead load. The effect of horizontal movement of the supports and the initial deformation state (sagging in the middle of a span) of the ribbons are accounted for as well.

2.2. Symmetrical Loading. The calculation scheme is presented in Figure 1. The vertical displacements of the strips, the horizontal displacements of the supports, and the tension forces in the bands are the unknowns. The length of the leftmost strip due to the elastic deformation can be calculated by the following formula [17-19]:

$$
s_{1}=L_{1}-\Delta h-\Delta L_{1}+\frac{8 \cdot\left(f_{01}+\Delta f_{1}\right)^{2}}{3 \cdot L_{1}},
$$

where $f_{01}$ is the sag of the leftmost ribbon; $\Delta f_{1}$ is the vertical displacement of the middle point of the leftmost ribbon; $L_{1}$ is the span; $\Delta L_{1}$ is the horizontal displacement of the leftmost support; $\Delta h$ is the displacement of the middle support. Taking an expression of the length of the unloaded strip into account, (1) can be rearranged as

$$
\begin{aligned}
\Delta f_{1}^{2}+ & 2 f_{01} \cdot \Delta f_{1}-\frac{3}{8} L_{1}\left(\Delta h+\Delta L_{1}\right) \\
& -\frac{3\left(H_{1}-H_{01}\right) L_{1}^{2}}{8 \cdot E A}=0
\end{aligned}
$$

where the tension (thrust) forces in the leftmost strip due to the complex action of the distributed dead and live loads $(g+$ p) can be expressed as

$$
H_{1}=\frac{(g+p)\left(L_{1}-\Delta h-\Delta L_{1}\right)^{2}}{8\left(f_{01}+\Delta f_{1}\right)},
$$

while the thrust force associated with the effect of the dead load $g$ can be obtained from the following:

$$
H_{01}=\frac{g \cdot L_{1}^{2}}{8 \cdot f_{01}} .
$$

Here $E A$ is the axial stiffness of the band; $p$ is the effective (live) load.

Using expressions (3) and (4), (2) can be expressed as a third-order polynomial

$$
\begin{aligned}
\Delta f_{1}^{3} & +3 f_{01} \Delta f_{1}^{2}+2 f_{01}^{2} \Delta f_{1} \\
& -\frac{3 L_{1}}{8}\left(\Delta h+\Delta L_{1}\right)\left(f_{01}+\Delta f_{1}\right) \\
& +\frac{3 L_{1}^{2}\left(L_{1}-\Delta h-\Delta L_{1}\right)^{2}}{64 E A}\left[g+p-\frac{g\left(f_{01}+\Delta f_{1}\right)}{f_{01}}\right]
\end{aligned}
$$


that can be solved with regard to the vertical displacement $\Delta f_{1}$ of the middle point of the strip:

$$
C_{3} \Delta f_{1}^{3}+C_{2} \Delta f_{1}^{2}+C_{1} \Delta f_{1}+C_{0}=0
$$

where the coefficients are given as

$$
\begin{aligned}
C_{3} & =1 ; \\
C_{2} & =3 f_{01} ; \\
C_{1} & =2 f_{1}^{2}-\frac{3}{8} L_{1}\left(\Delta h+\Delta L_{1}\right) \\
& +\frac{3 g L_{1}^{2}\left(L_{1}-\Delta h-\Delta L_{1}\right)^{2}}{64 E A \cdot f_{01}} ; \\
C_{0} & =-\frac{3 L_{1}}{8}\left[f_{01}\left(\Delta h+\Delta L_{1}\right)\right. \\
& \left.+\frac{(g+p) L_{1}\left(L_{1}-\Delta h-\Delta L_{1}\right)^{2}}{8 E A}-\frac{g L_{1}^{3}}{8 E A}\right] .
\end{aligned}
$$

The polynomial (6) has three roots. From the condition that the minimum root should be a positive number, the solution becomes as follows:

$$
\begin{aligned}
\Delta f_{1} & =\frac{1}{3 C_{3}}(2 \bar{C} \\
\cdot & \cos \left\{\frac{1}{3} \arccos \left[-\frac{27 C_{3}^{2} C_{0}-9 C_{3} C_{2} C_{1}+2 C_{2}^{3}}{2 \bar{C}^{3}}\right]\right\} \\
& \left.-C_{2}\right), \quad \bar{C}=\sqrt{C_{2}^{2}-3 C_{3} C_{1}} .
\end{aligned}
$$

However, the solution process could be iterative as the variation of $\Delta f_{1}$ causes changes in the support displacements $\Delta h$ and $\Delta L_{1}$.

If $\Delta f_{1}$ is known, the displacement of the middle point of the rightmost strip can be defined as

$$
\begin{aligned}
\Delta f_{2} & =-f_{02} \\
& +\frac{(g+p) f_{01} \cdot f_{02}\left(f_{01}+\Delta f_{1}\right) L_{1}^{2}}{(g+p) f_{01} f_{02} L_{1}^{2}+g\left(f_{01}+\Delta f_{1}\right)\left(L_{2}^{2} f_{01}-L_{1}^{2} f_{02}\right)} .
\end{aligned}
$$

Hereafter all symbols are similar to the previously described notations with the subscripts " 2 " and " 02 ," which are related to the rightmost span. The above expression was defined under the equality condition of the thrust forces in both strips:

$$
H_{1}-H_{01}=H_{2}-H_{02} \text {. }
$$

The thrust force in the deformed rightmost strip under the common action of the dead and live load can be determined as

$$
H_{2}=\frac{(g+p)\left(L_{2}+\Delta h-\Delta L_{2}\right)^{2}}{8\left(f_{02}+\Delta f_{2}\right)}
$$

The initial force (induced by the dead load) can be assessed as

$$
H_{02}=\frac{g \cdot L_{2}^{2}}{8 \cdot f_{02}} .
$$

The horizontal displacement of the intermediate support $\Delta h$ can be obtained by accounting for the differences of the initial and final elongations of the strips:

$$
\Delta h=s_{01}-s_{02}=\left(s_{1}-\Delta s_{\mathrm{el}, 1}\right)-\left(s_{2}-\Delta s_{\mathrm{el}, 2}\right) .
$$

Here $\Delta s_{\mathrm{el}, 1}$ and $\Delta s_{\mathrm{el}, 2}$ are the elastic elongations of the ribbons. Formula (13) can be expressed in terms of vertical displacements and thrust forces as follows:

$$
\begin{aligned}
\Delta h= & \frac{\Delta L_{2}-\Delta L_{1}}{2} \\
& +\frac{4}{3}\left(\frac{2 f_{01} \cdot \Delta f_{1}+\Delta f_{1}^{2}}{L_{1}}-\frac{2 f_{02} \cdot \Delta f_{2}+\Delta f_{2}^{2}}{L_{2}}\right) \\
& -\frac{\left(H_{1}-H_{01}\right) \cdot L_{1}}{2 \cdot E A}+\frac{\left(H_{2}-H_{02}\right) \cdot L_{2}}{2 \cdot E A} .
\end{aligned}
$$

Horizontal displacements of the boundary supports can be obtained from

$$
\begin{aligned}
& \Delta L_{1}=\frac{H_{1}}{c_{1}} ; \\
& \Delta L_{2}=\frac{H_{2}}{c_{2}},
\end{aligned}
$$

where $c_{1}$ and $c_{2}$ are the stiffness values of the left and right supports, respectively.

Since the vertical displacements $\Delta f_{1}$ and $\Delta f_{2}$ are known, the respective displacements at the quarters of the spans $\left(x_{1}=\right.$ $L_{1} / 4$ and $x_{2}=L_{2} / 4$; see Figure 1) can be calculated by using the following relationships:

$$
\begin{aligned}
& z_{1}\left(x_{1}\right)=4 \frac{\Delta f_{1} \cdot x_{1}}{L_{1}}\left(1-\frac{x_{1}}{L_{1}}\right) ; \\
& z_{2}\left(x_{2}\right)=4 \frac{\Delta f_{2} \cdot x_{2}}{L_{2}}\left(1-\frac{x_{2}}{L_{2}}\right) .
\end{aligned}
$$

The iterative calculations are started by assuming horizontal displacements of all supports equal to zero (i.e., $\Delta h=$ $\left.\Delta L_{1}=\Delta L_{2}=0\right)$. The vertical displacements of the middle points of both strips are determined by using (8) and (9). Then, the horizontal displacements of the supports are obtained through expressions (14) and (15). The iterations are repeated until the variation of the displacement of the intermediate support falls within the assumed convergence tolerance $\Delta$ :

$$
\left|\Delta h_{n}-\Delta h_{n+1}\right| \leq \Delta .
$$

Here $n$ and $n+1$ define the iteration numbers. 


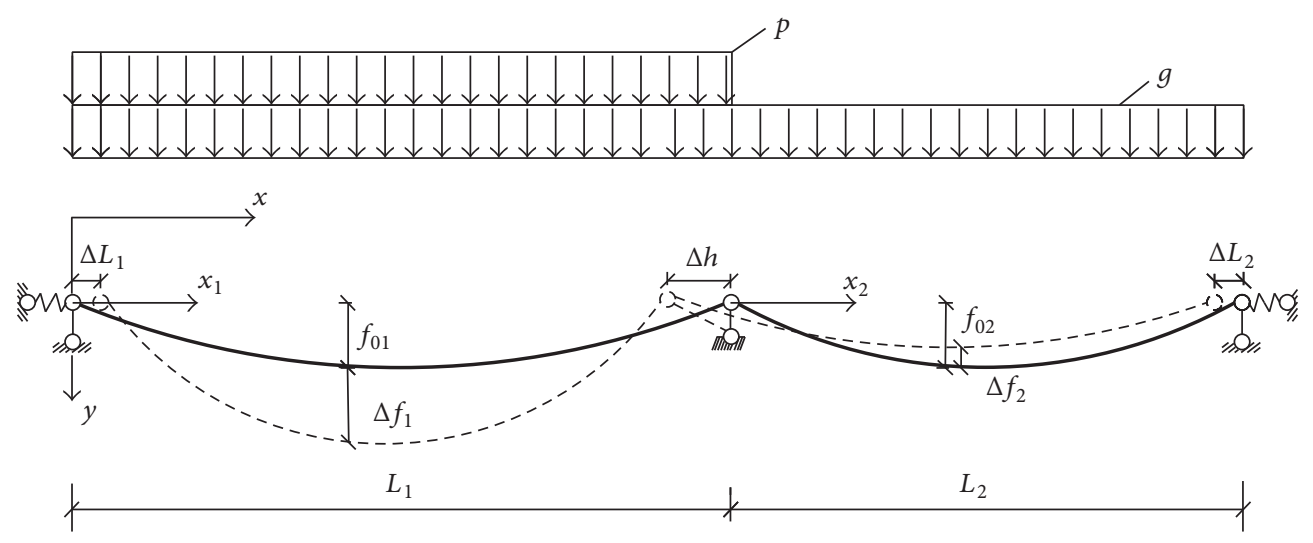

FIgURE 2: The calculation scheme of the stress-ribbon system subjected to asymmetrical loading.

2.3. Asymmetrical Loading. The asymmetrical loading scheme is shown in Figure 2. As can be observed, the loading layout is related to the distribution of the live load $p$ over the leftmost span of the bridge. As mentioned in Section 2.1, the deformation behaviour of the stress-ribbon is closely related to the elastic and kinematic displacement components. In the case of asymmetrical loading, the contribution of the latter component becomes more significant.

2.3.1. Kinematic Displacements. For simplicity, the kinematic displacements are determined by neglecting the elastic elongations of the ribbons (i.e., $\Delta s_{\mathrm{el}, 1}=\Delta s_{\mathrm{el}, 2}=0$ ). Accounting only for the effect of the dead load in expression (11), the vertical kinematic displacement of the middle point of the leftmost strip can be assessed from condition (10) as

$$
\begin{aligned}
\Delta f_{1 k} & \\
= & -f_{01} \\
& \quad+\frac{(g+p) f_{01} \cdot f_{02}\left(f_{02}+\Delta f_{2 k}\right) L_{1}^{2}}{g f_{01} f_{02} L_{2}^{2}+g\left(f_{02}+\Delta f_{2 k}\right)\left(L_{1}^{2} f_{02}-L_{2}^{2} f_{01}\right)} .
\end{aligned}
$$

The respective thrust force is determined by using (3) with the elastic displacements $\Delta h, \Delta L_{1}$, and $\Delta f_{1}$ replaced by the kinematic equivalents.

Similar conditions result in the following expression of the vertical kinematic displacement of the rightmost strip:

$$
\Delta f_{2 k}=-f_{02}+\frac{g \cdot f_{01} f_{02} L_{2}^{2} \sqrt{f_{01}^{2}+3 / 8 L_{1}\left(\Delta L_{1}+\Delta h_{k}\right)}}{(g+p) f_{01} f_{02} L_{1}^{2}+g\left(L_{2}^{2} f_{01}-L_{1}^{2} f_{02}\right) \sqrt{f_{01}^{2}+3 / 8 L_{1}\left(\Delta L_{1}+\Delta h_{k}\right)}} .
$$

The horizontal kinematic displacement of the intermediate support is determined from (13) by accounting for the aforementioned simplification $\left(\Delta s_{\mathrm{el}, 1}=\Delta s_{\mathrm{el}, 2}=0\right)$ and assuming that the length of the rightmost strip is defined as

$$
s_{2}=L_{2}+\Delta h_{k}-\Delta L_{2}+\frac{8 \cdot\left(f_{02}+\Delta f_{2 k}\right)^{2}}{3 \cdot L_{2}}
$$

The resultant expression of the kinematic displacement is then determined by

$$
\begin{aligned}
& \Delta h_{k} \\
& =0.5\left(\Delta L_{2}-\Delta L_{1}\right) \\
& \quad+\frac{4}{3}\left(\frac{\Delta f_{1 k}^{2}+2 \Delta f_{1 k} \cdot f_{01}}{L_{1}}-\frac{\Delta f_{2 k}^{2}+2 \Delta f_{2 k} \cdot f_{02}}{L_{2}}\right) .
\end{aligned}
$$

The iterative calculation principles are identical to the described ones in the previous section. In the first iteration, all horizontal displacements of the supports are neglected. The vertical kinematic displacements of both strips are determined by using (18) and (19). Expressions (15) and (21) define the respective displacement of the supports. The iterations are carried out until the convergence criterion (17) is satisfied.

2.3.2. Total Displacements. The total displacements are determined by accounting for the kinematic and elastic components, while the initial state is associated with the release of the kinematic deformations $[9,10]$. Consequently, the initial length of the leftmost strip is determined as

$$
s_{01 k}=L_{1}-\Delta h_{k}-\Delta L_{1}+\frac{8}{3} \frac{f_{01 k}^{2}}{L_{1}}
$$


where $f_{01 k}$ is the initial sag of the leftmost strip that is calculated as

$$
f_{01 k}=f_{01}+\Delta f_{1 k}
$$

The same expressions (replacing the respective indices) are used for determining the length $s_{02 k}$ and the sag $f_{02 k}$ of the rightmost strip.

The length of the leftmost strip after the elastic deformation is defined as

$$
s_{1}=L_{1}-\Delta h-\Delta L_{1}+\frac{8 \cdot\left(f_{01 k}+\Delta f_{1 \mathrm{el}}\right)^{2}}{3 \cdot L_{1}} .
$$

This formula can be rearranged as

$$
\begin{aligned}
\Delta f_{1 \mathrm{el}}^{2} & +2 f_{01 k} \cdot \Delta f_{1 \mathrm{el}}-\frac{3}{8} L_{1 \mathrm{el}}\left(\Delta h-\Delta h_{k}\right) \\
& -\frac{3\left(H_{1}-H_{01}\right) \cdot L_{1}^{2}}{8 \cdot E A}=0
\end{aligned}
$$

where, similarly to (3), the thrust force is expressed as

$$
H_{1}=\frac{(g+p)\left(L_{1}-\Delta h-\Delta L_{1}\right)^{2}}{8\left(f_{01 k}+\Delta f_{1 \mathrm{el}}\right)},
$$

and, in the same manner as it was done in Section 2.2, the third-order polynomial can be obtained:

$$
\begin{aligned}
& \Delta f_{1 \mathrm{el}}^{3}+3 f_{01 k} \Delta f_{1 \mathrm{el}}^{2}+2 f_{01 k}^{2} \Delta f_{1 \mathrm{el}} \\
& +\frac{3 L_{1}^{2}\left(f_{01 k}+\Delta f_{1 \mathrm{el}}\right)}{8}\left[\frac{\Delta h_{k}-\Delta h-\Delta L_{1}+\Delta L_{1 k}}{L_{1}}\right. \\
& \left.+\frac{g L_{1}^{2}}{8 f_{01} E A}-\frac{(g+p)\left(L_{1}-\Delta h-\Delta L_{1}\right)^{2}}{8 E A\left(f_{01 k}+\Delta f_{1 \mathrm{el}}\right)}\right]=0 .
\end{aligned}
$$

The equation with regard to the elastic displacement $\Delta f_{1 \mathrm{el}}$, identical to formula (6), has the following coefficients:

$$
\begin{aligned}
C_{3} & =1 ; \\
C_{2} & =3 f_{01 k} ; \\
C_{1} & =2 f_{01 k}^{2}+\frac{3}{8} L_{1}^{2}\left[\frac{\Delta h_{k}-\Delta h-\Delta L_{1}+\Delta L_{1 k}}{L_{1}}\right. \\
& \left.+\frac{g L_{1}^{2}}{8 f_{01} E A}\right] ; \\
C_{0} & =\frac{3}{8} \\
& \cdot L_{1}^{2}\left[f_{01 k}\left(\frac{\Delta h_{k}-\Delta h-\Delta L_{1}+\Delta L_{1 k}}{L_{1}}+\frac{g L_{1}^{2}}{8 f_{01} E A}\right)\right. \\
& \left.-\frac{(g+p)\left(L_{1}-\Delta h-\Delta L_{1}\right)^{2}}{8 E A}\right] .
\end{aligned}
$$

Equation (8) determines the solution of the polynomial (27).
In case of asymmetrical loading (Figure 2), the thrust force in the rightmost strip, similar to (8), is determined by accounting for the effect of dead load only:

$$
H_{2}=\frac{g\left(L_{2}+\Delta h-\Delta L_{2}\right)^{2}}{8\left(f_{02 k}+\Delta f_{2 \mathrm{el}}\right)} .
$$

A formula similar to (9) describes the vertical displacement of the rightmost strip related to the elastic deformation component:

$$
\begin{aligned}
& \Delta f_{\text {2el }}=-f_{02 k} \\
& \quad+\frac{g\left(f_{01 k}+\Delta f_{1 \mathrm{el}}\right) f_{02} f_{01} L_{2}^{2}}{(g+p) f_{02} f_{01} L_{1}^{2}-g\left(f_{01 k}+\Delta f_{1 \mathrm{el}}\right)\left(L_{1}^{2} \cdot f_{02}-L_{2}^{2} \cdot f_{01}\right)} .
\end{aligned}
$$

If kinematic $\Delta f_{1 k}$ and $\Delta f_{2 k}$, and elastic $\Delta f_{1 \mathrm{el}}$ and $\Delta f_{2 \mathrm{el}}$ displacements are known, the total vertical displacements of both strips are determined as

$$
\begin{aligned}
& \Delta f_{1}=\Delta f_{1 k}+\Delta f_{1 \mathrm{el}} \\
& \Delta f_{2}=\Delta f_{2 k}+\Delta f_{2 \mathrm{el}} .
\end{aligned}
$$

The horizontal displacement of the intermediate support due to the combined action of the kinematic and elastic components is obtained from

$\Delta h$

$$
\begin{aligned}
= & \Delta h_{k}+\frac{\Delta L_{2}-\Delta L_{1}-\Delta L_{2 k}+\Delta L_{1 k}}{2} \\
& +\frac{4}{3}\left(\frac{2 f_{01 k} \Delta f_{1 \mathrm{el}}+\Delta f_{1 \mathrm{el}}^{2}}{L_{1}}-\frac{2 f_{02 k} \Delta f_{2 \mathrm{el}}+\Delta f_{2 \mathrm{el}}^{2}}{L_{2}}\right) \\
& -\frac{\left(H_{1}-H_{01}\right) L_{1}}{2 \cdot E A}+\frac{\left(H_{2}-H_{02}\right) L_{2}}{2 \cdot E A} .
\end{aligned}
$$

The same iterative calculation principles as described previously are used for achieving convergence that is described by (17). The total vertical displacements are determined by (31).

\section{Tests of the Bridge Model}

A physical model of the stress-ribbon bridge with two spans (each of them equal to five meters) has been tested in 2014 in the Structural Laboratory at VGTU. The main aim of this test was to validate the adequacy of the proposed analytical technique for the case when flexural steel bands are used as the stress-ribbons.

A two-span stress-ribbon 3D structure shown in Figure 3 represents the bridge model. The layout of the ribbons and supports is schematically presented in Figure 4. As shown, the total length of the model is equal to $10 \mathrm{~m}$. The boundary supports allow for the rotation of the bands but prevent horizontal displacement of the connection joints, whereas the intermediate support allows both, rotation and horizontal displacement of the ribbons. The steel bands were made of $6 \mathrm{~mm}$ thickness sheets with a width of $80 \mathrm{~mm}$. The steel grade 


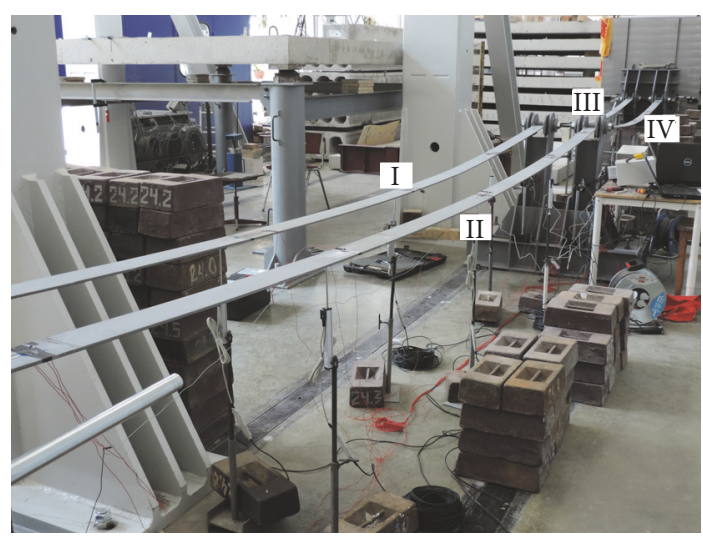

(a)

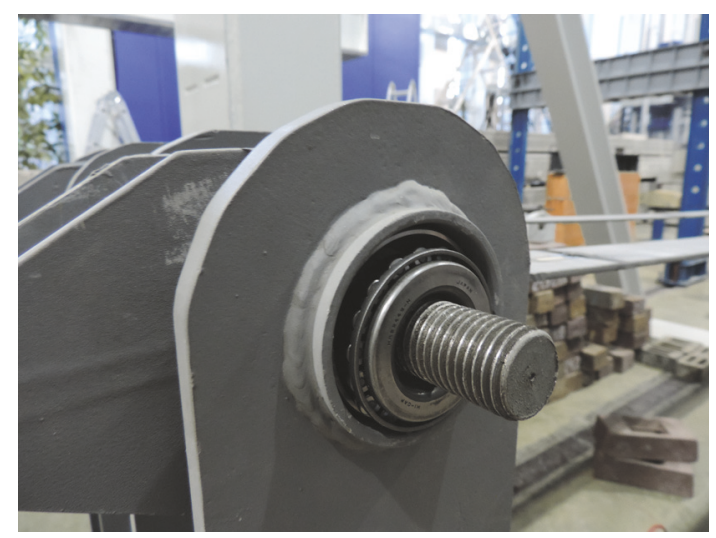

(b)

FIGURE 3: Steel bands (numbered items) of the bridge model (a) and ribbon anchorage joint (b).

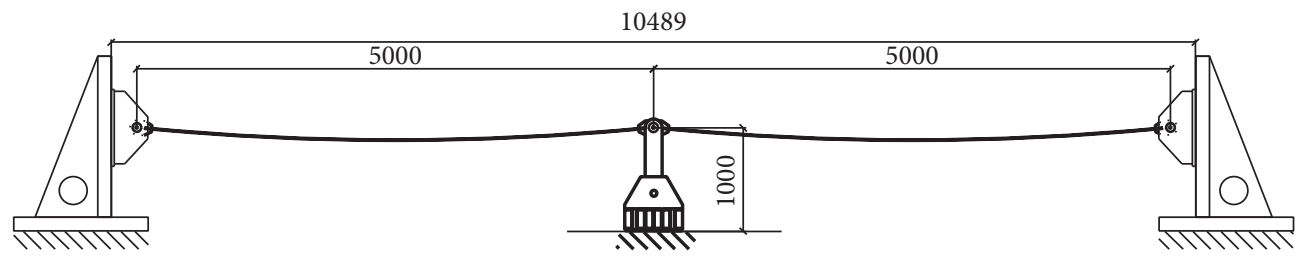

FIGURE 4: The structural layout of the stress-ribbon bridge model.

S355 was used for this purpose. The elasticity modulus of the steel was determined experimentally by following EN 10002-1 standard methodology. Three steel samples were tested revealing the average modulus of elasticity $E_{c}=208 \mathrm{GPa}$. It is assumed that the initial shape of the bands can be defined by a second-order polynomial. Due to production inaccuracies, the length of the bands was slightly different. Before construction of the model, the bands were grouped in two spans by length. The following initial sags, induced by the self-weight of the strips (equal to $23.5 \mathrm{~kg}$ for each band), were determined for the model: $\bar{f}_{01} \approx \bar{f}_{02}=L / 40.48$ and $\bar{f}_{03} \approx \bar{f}_{04}=L / 39.77$.

The bridge model was subjected to uniformly distributed loads of different configuration. Symmetrical and asymmetrical loading layouts were applied over several steps. The ultimate load was set as $40 \%$ of the theoretical load carrying capacity of the model. At the first load step, a wooden deck was placed on the bridge model. At the successive load steps, each span of the model was loaded by approximately $365 \mathrm{~kg}$. The loading was induced by using metal weights with an average weight of $23.5 \mathrm{~kg}$.

The maximum symmetrical load was reached within nine loading steps. The first step induced a distributed load of $81.1 \mathrm{~N} / \mathrm{m}$, the second step $-813.6 \mathrm{~N} / \mathrm{m}$, and so on. The final loading step shown in Figure 5 (a) results in a $5.915 \mathrm{kN} / \mathrm{m}$ load. The loads include the deal load of the wooden spreader beam, while the self-weight of the ribbons is neglected. The asymmetrical load was applied on the bridge model with different ratios of the live and dead load components $(\gamma=p / g)$. Initially, the bridge was subjected to a dead load distributed through both spans, then the live load component was distributed over the leftmost span (Figure 4). The maximum asymmetrical load was applied in two configurations: (1) $p=2.982 \mathrm{kN} / \mathrm{m}$ and $g=3.005 \mathrm{kN} / \mathrm{m}(\gamma \approx 1)$; (2) $p=$ $4.006 \mathrm{kN} / \mathrm{m}$ and $g=1.987 \mathrm{kN} / \mathrm{m}(\gamma \approx 2)$. The latter loading layout is shown in Figure 5(b).

Two types of devices were used for monitoring deformations and displacements of the ribbons. The displacements were measured by using $25 \mathrm{~mm}$ linear variable displacement transducers (LVTD, with $0.01 \mathrm{~mm}$ accuracy), while the deformations were monitored by $20 \mathrm{~mm}$ strain gauges (with $0.01 \%$ accuracy). The arrangement schemes of devices are shown in Figure 6 with geometrical properties given in Figure 7. As can be observed in Figure 6(a), 23 LVDT were distributed below the stress-bands and near the supports: twelve indicators measured vertical displacements of the ribbons; six LVDT were used to monitor horizontal displacements of the supports (two per support); the remaining five devices were used to control the position of the supports during the test. The strain gauges (Figure 6(b)) were used to monitor deformations of the steel bands. Monitoring data was recorded at both, loading and unloading stages.

The deformation monitoring results reveal that the flexibility parameter

$$
k L=L \sqrt{\frac{H}{E I}}
$$

varied from 64 to 71 (depending on the loading conditions). In the above equation, $H$ is the thrust force and $E I$ is the 


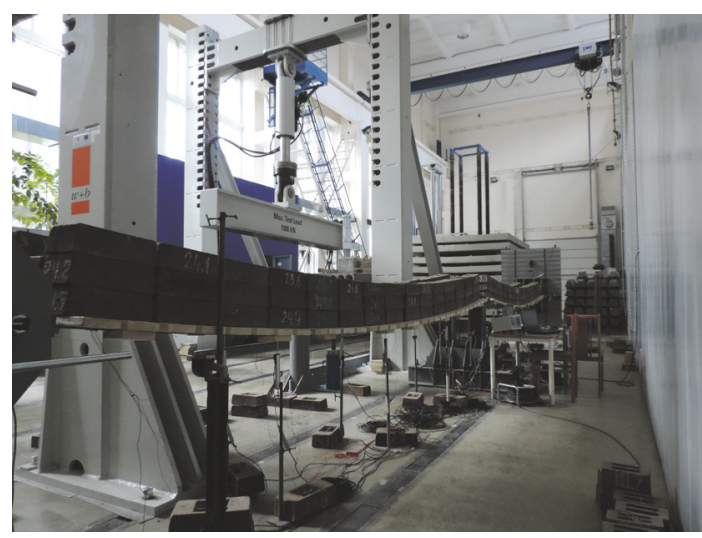

(a)

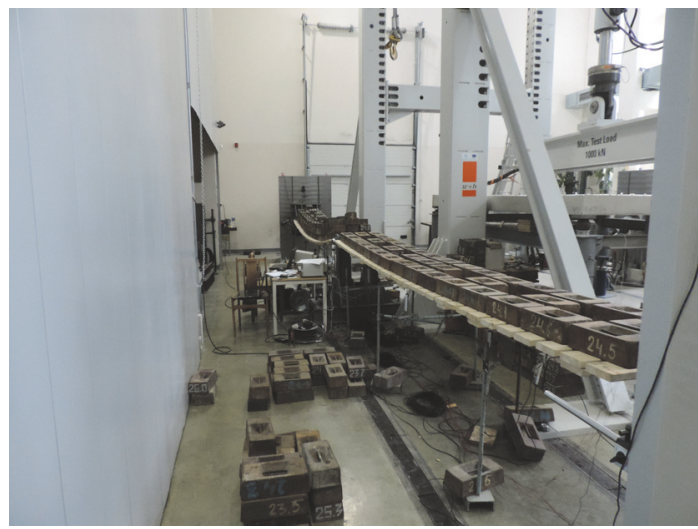

(b)

Figure 5: The maximum loading stages: symmetrical load (a); asymmetrical load (b).

flexural stiffness of the band. Since $k L$ is well above 10 , the band can be considered as fully flexible, that is, $E I \rightarrow 0$ [9].

\section{Discussion of the Results}

The analysis is based on monitoring results of II and IV bands (Figure 4) as the symmetric ribbons (i.e., I and III) possess identical outputs. The vertical displacements of the bridge subjected to symmetrical loading $(g+p=5.915 \mathrm{kN} / \mathrm{m})$ are presented in Table 1 (location of the indicators is shown in Figure 6(a)). The analytical calculations (Section 2.2) were carried out by referring the initial analysis stage to the stressstrain state realized after application of the dead load ( $g=$ $3.0 \mathrm{kN} / \mathrm{m})$. Therefore, Table 1 presents two components of the vertical displacement: the initial component related to the dead load was identified as the sag $\left(f_{0}\right)$, while the increment $\Delta f$ was attributed to the application of the live load. Experimental values of horizontal boundary support displacements, corresponding to the load $p$, are presented in Table 2.

The results presented in Table 1 reveal that the maximum inaccuracy of the predictions reaches $11.6 \%$. This might be associated with a certain disagreement between the initial outline of the band and the parabolic shape assumed in the
TABLE 1: Test results and analytical predictions of vertical displacements due to symmetrical load.

\begin{tabular}{lcccc}
\hline Indicator & \multirow{2}{*}{ Sag $f_{0}, \mathrm{~mm}$} & Test & $\begin{array}{c}\Delta f, \mathrm{~mm} \\
\text { Prediction }\end{array}$ & Error, \% \\
\hline I2 & - & -8.92 & -8.99 & -0.8 \\
I3 & -138.80 & -10.74 & -11.99 & 11.6 \\
I4 & - & -8.18 & -8.80 & 9.9 \\
I11 & - & -9.65 & -8.60 & -10.9 \\
I12 & -140.10 & -11.77 & -11.46 & -2.6 \\
I13 & - & -8.85 & -8.60 & -2.8 \\
\hline
\end{tabular}

TABLE 2: Horizontal displacement of boundary supports $\Delta L, \mathrm{~mm}$.

\begin{tabular}{lccc}
\hline \multirow{2}{*}{ Indicator } & Symmetrical load & \multicolumn{2}{c}{ Asymmetrical load } \\
& & $\gamma \approx 1$ & $\gamma \approx 2$ \\
\hline I1 & 0.13 & 0.07 & 0.11 \\
I14 & 0.75 & 0.09 & 0.20 \\
\hline
\end{tabular}

analytical model. However, the average prediction error (less than $1 \%$ ) indicates the accuracy of the analytical model to be adequate for predicting displacements of the stress-ribbons. The comparative analysis of the mean stresses in the ribbons (using the strain gauge data) reveals improved accuracy over results obtained from the displacements: all inadequacies fall within the $1.5 \%$ interval with the exception of one result (associated with the gauges T1/T2, Figure 6(b)) that the prediction error was equal to $5.0 \%$. It might be addressed to local effects due to friction in the support joint. Assessment of the thrust forces is precise: the difference between experimental $(60.89 \mathrm{kN})$ and analytical $(60.94 \mathrm{kN})$ load is marginal (0.1\%). This load was calculated by (3) and (11).

The displacement results obtained under different live and dead load ratios $\gamma$ are compared in Table 3. The vertical displacement results of the bridge subjected to asymmetrical loading $(\gamma \approx 2)$ are shown in Figure 8 . The analytical modelling (Section 2.3), similarly to the symmetrical loading case, is related to the stressed state realized after the application of the dead load $g$ and characterized by the sag $f_{0}$ (Table 3 ). The horizontal displacements $\Delta L$ associated with the application of the load $p$ are given in Table 2 .

As can be observed in Table 3 , the prediction accuracy is similar to that observed for the symmetrical loading: the average prediction error varies from $0.6 \%$ to $2.3 \%$ (depending on the ratio $\gamma$ ), while the respective maximum errors are equal to $7.4 \%$ and $13.1 \%$. The observed maximal error values are related to the span that was not subjected to the live load (Figure 5(b)). It is also evident that the deformed shape of the band differs from the theoretical model (Figure 8). The construction imperfections, including friction in the support joints (Figure 3(b)) and uneven distribution of the stresses in parallel ribbons, may cause such an outcome. In contrast to the vertical displacement results, the horizontal displacements of the intermediate support are predicted precisely: the prediction error varies from $0.4 \%$ to $2.3 \%$ depending on the 


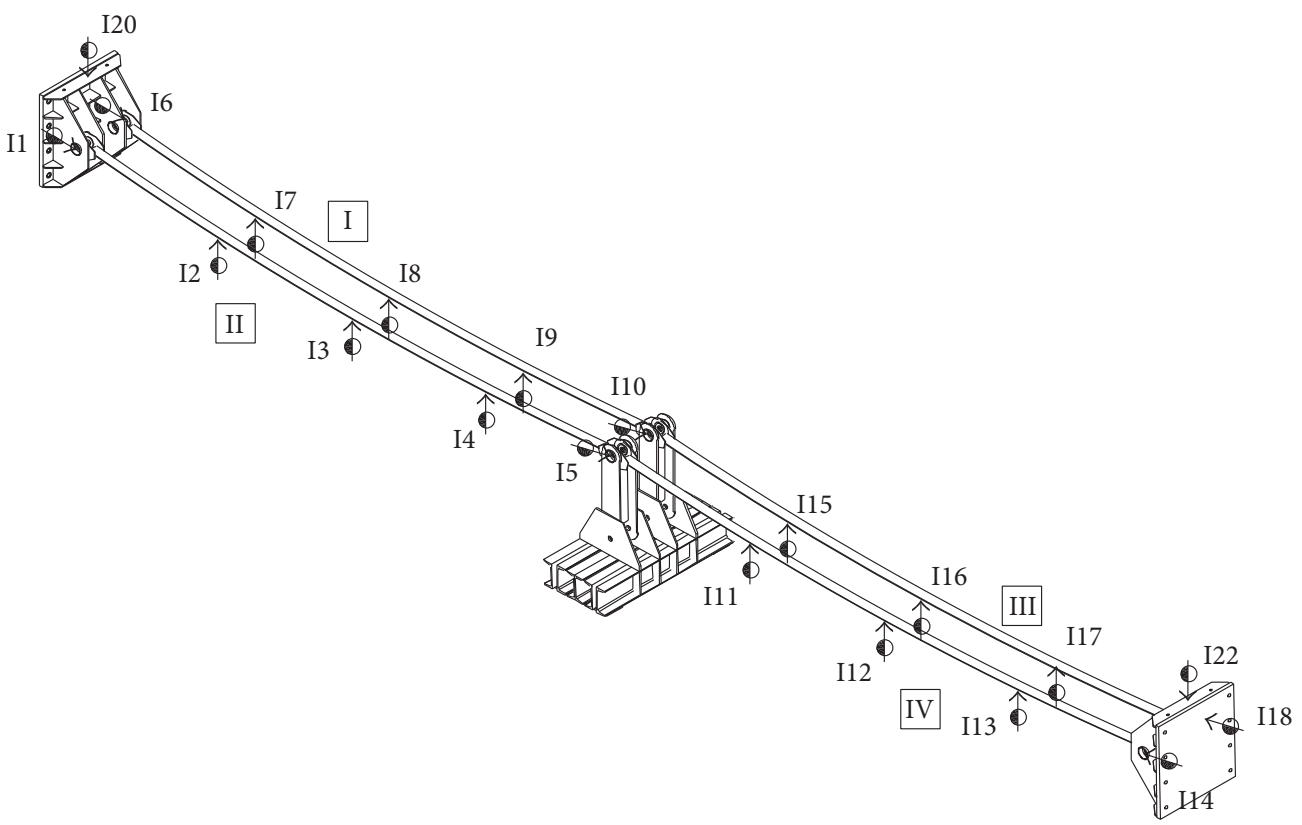

(a)

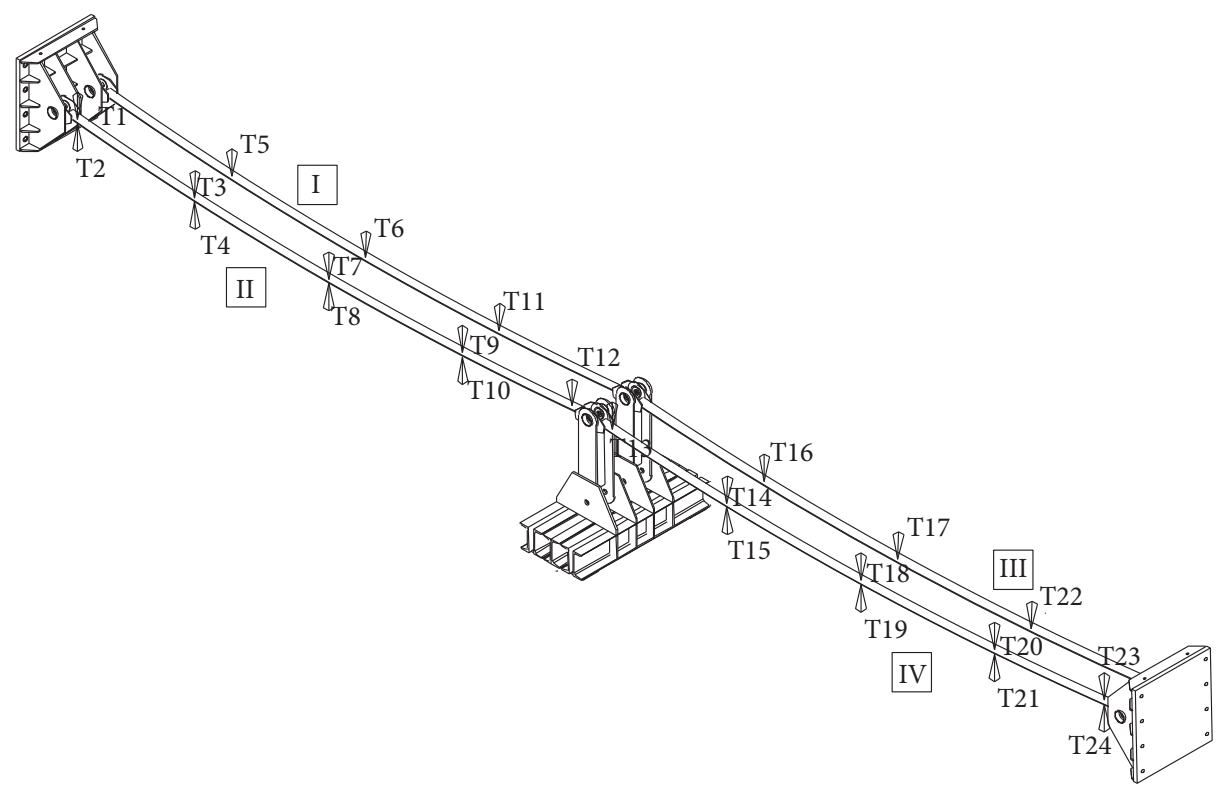

(b)

Figure 6: Distribution of the monitoring devices: LVDT (a); strain gauges (b).

ratio between live and dead loads. The thrust forces are also assessed accurately: the prediction errors are equal to $-0.6 \%$ and $-3.1 \%$ for the loading cases with the ratios $\gamma \approx 1$ and $\gamma \approx 2$, respectively.

Horizontal displacements of the supports and the predicted vertical displacements of the mid-point of the ribbon are correlated. The maximum experimental displacements of the supports during the symmetrical and asymmetrical loadings were approximately evaluated as $L / 1500$ and $L / 1800$, respectively. Theoretical modelling revealed that such displacements cause a $20 \%-24 \%$ increase of the vertical displacement.

The test results reveal that the maximum thrust forces $(60.89 \mathrm{kN})$ are associated with the symmetrical loading. In asymmetrical combinations with different $\gamma$, the respective values of the force were equal to $51.04 \mathrm{kN}$ and $49.14 \mathrm{kN}$. However, the maximum vertical displacement is related to the asymmetrical distribution of the load. It is a consequence of the kinematic deformations. 
TABLE 3: Test results and analytical predictions of vertical displacements due to asymmetrical load.

\begin{tabular}{|c|c|c|c|c|c|c|c|c|}
\hline \multirow{3}{*}{ Indicator } & \multirow{3}{*}{$\operatorname{Sag} f_{0}, \mathrm{~mm}$} & \multicolumn{3}{|c|}{$\gamma \approx 1$} & \multirow{3}{*}{$\operatorname{Sag} f_{0}, \mathrm{~mm}$} & \multicolumn{2}{|c|}{$\gamma \approx 2$} & \multirow{3}{*}{ Error, \% } \\
\hline & & \multicolumn{2}{|c|}{$\Delta f, \mathrm{~mm}$} & \multirow{2}{*}{ Error, \% } & & \multicolumn{2}{|c|}{$\Delta f, \mathrm{~mm}$} & \\
\hline & & Test & Prediction & & & Test & Prediction & \\
\hline $\mathrm{I} 2$ & - & -33.77 & -32.91 & -2.5 & - & -45.38 & -44.69 & -3.7 \\
\hline I3 & -142.67 & -46.67 & -43.90 & -5.9 & -137.84 & -60.82 & -58.25 & -4.2 \\
\hline I4 & - & -33.47 & -32.91 & -1.7 & - & -44.92 & -44.69 & -2.7 \\
\hline I11 & - & 34.34 & 35.75 & 4.1 & - & 50.81 & 54.39 & 7.0 \\
\hline $\mathrm{I} 12$ & -141.25 & 46.55 & 47.67 & 2.4 & -138.06 & 69.78 & 72.52 & 3.9 \\
\hline I13 & - & 33.28 & 35.75 & 7.4 & - & 48.10 & 54.39 & 13.1 \\
\hline \multicolumn{9}{|c|}{ Horizontal displacement $\Delta h, \mathrm{~mm}$} \\
\hline I5 & - & -6.90 & -6.84 & -0.9 & - & -9.14 & -9.16 & 0.2 \\
\hline
\end{tabular}

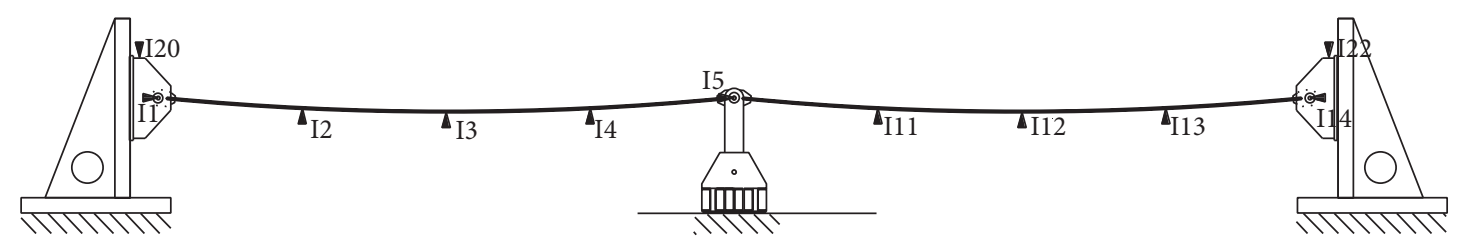

(a)

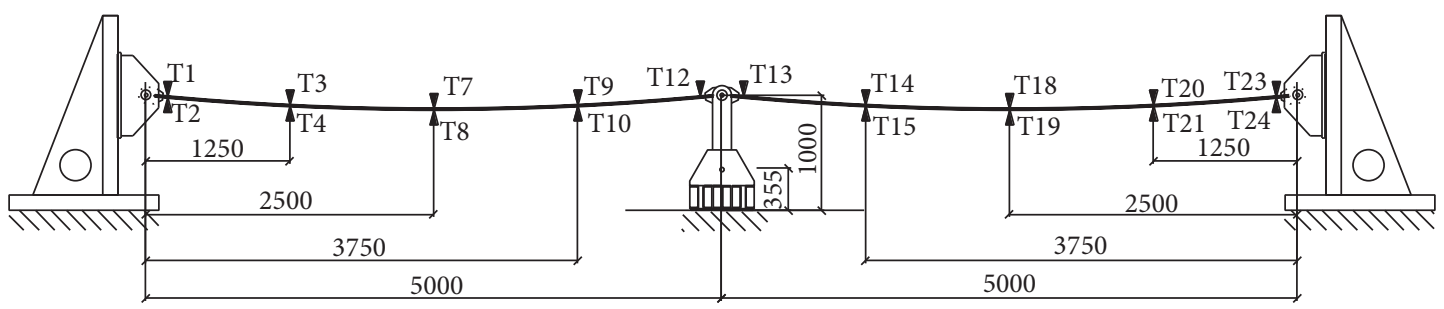

(b)

FIGURE 7: Geometrical properties of distribution of the monitoring devices: LVDT (a); strain gauges (b).

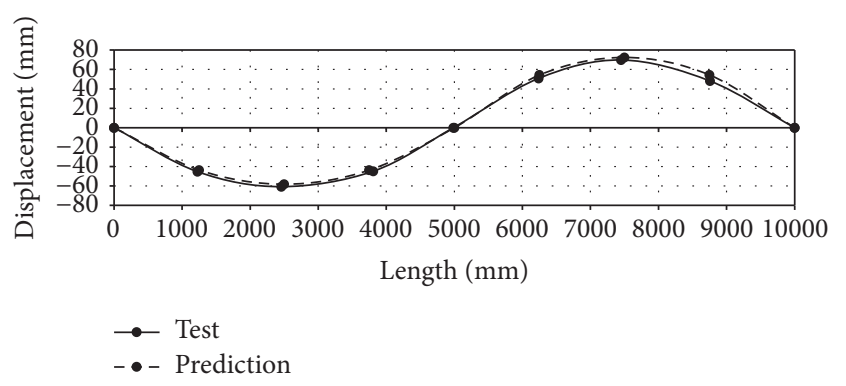

FIGURE 8: Vertical displacements of the bridge subjected to asymmetrical loading $(\gamma \approx 2)$.

Another important finding related to the redistribution of deformations within the stress-band (assumed to be a perfectly flexible element). The tensile stresses assessed by using strain gauges are given in Table 4 (the location of the gauges is indicated in Figures 6(b) and 7(b)). The mean stresses in the strips (determined by averaging results of two gauges placed at opposite surfaces of the band) are assessed accurately: all prediction errors fall within a $4 \%$ interval. The stresses were theoretically estimated by relating the axial (cable) force with the cross-section area of the band. However, prediction inaccuracies noticeably increase by accounting for the redistribution of strains within the depth of the ribbon. The results of the gauges located at the most tensioned surfaces are

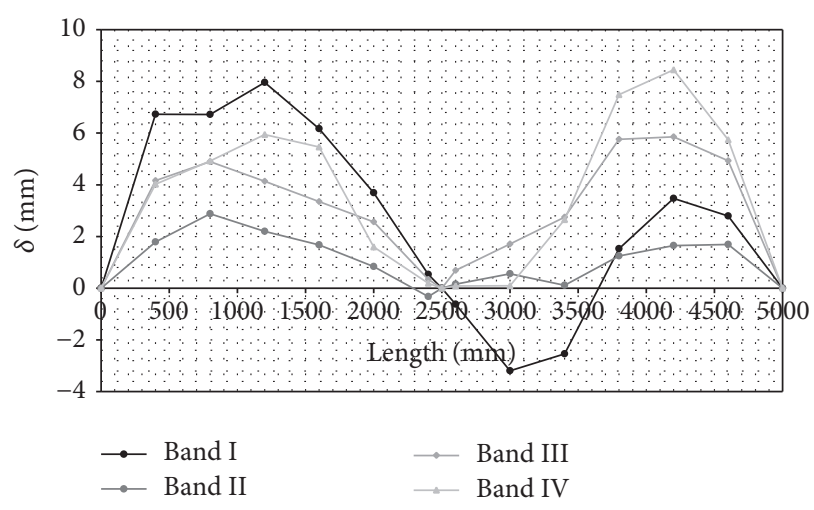

FIGURE 9: Geometry imperfection of the bands.

shown in italic font in Table 4. As can be observed the strain redistribution increases local stresses in the ribbons though the flexural stiffness is marginal $(E I \rightarrow 0)$.

The effect of shape imperfections of the bands on deformation behaviour of the stress-ribbon structures might also be identified as an important aspect that requires clarification. Figure 9 presents the difference $\delta$ between an ideal square parabola (with the same maximum sag $\bar{f}_{0}$ as a real band) and the actual geometric shape of the bands. The relative magnitude of such imperfections (Figure 9) might be noticeable 
TABLE 4: Tensile stresses in ribbons due to asymmetrical load [MPa].

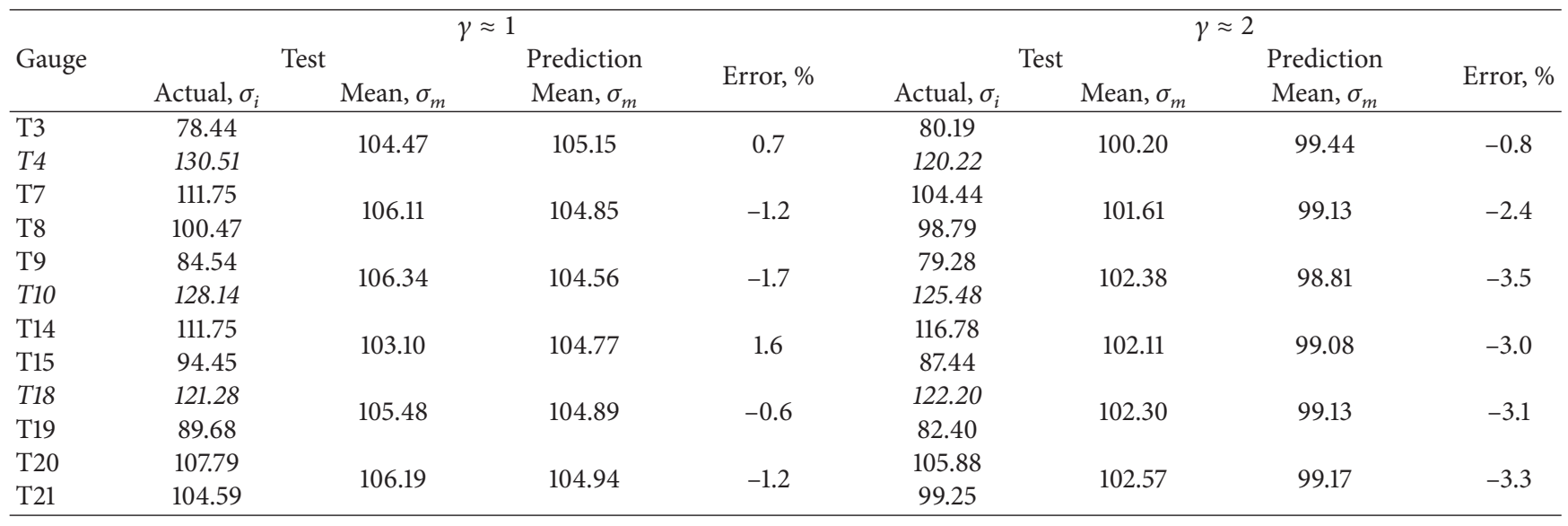

since the self-weight induced a sag $\bar{f}_{0} \approx 125 \mathrm{~mm}$. Shape imperfection effects are also closely related to the flexural stiffness of bands. Further research, therefore, should be dedicated to the analysis of such intertwined characteristics.

Due to the lack of relevant data published in the literature, the present experimental program could be considered as an important reference of the test data of stress-ribbon structures. The obtained results will have an impact on further research dedicated to the development of efficient composite structures [5].

\section{Conclusions}

The paper investigates the deformation behaviour of a twospan pedestrian stress-ribbon bridge with ribbons made of steel sheets, which are assumed to be perfectly flexible elements. An analytical technique was proposed for structural design. The predictions were validated against the experimental data of the bridge with a total span equal to $10 \mathrm{~m}$ tested within the framework of this study. The analysis reveals that

(1) adequacy of the proposed analytical technique was found to be acceptable for predicting the deformations and thrust forces of the stress-band: in most cases the prediction errors fall within a 5\% interval;

(2) To simplify the iterative calculations, the elastic and kinematic deformation components were separated;

(3) The kinematic component must be accounted for when carrying out analysis of an asymmetrical configuration of the loading scheme that could be related to the load distribution or structural characteristics (e.g., uneven spans, different stiffness of supports);

(4) Comparative analysis of the theoretical predictions reveals the importance of two commonly neglected factors related to the deformation behaviour of the stress-ribbon structures, namely, the production inaccuracies and flexural stiffness of the ribbons. Both factors cause a noticeable increase of the differences between an idealized and actual response of the bridge: errors of the predictions were doubled. In some cases, such an increase might lead to dramatic outcomes. Both aforementioned factors must be accounted for when developing mathematical models.

\section{Conflicts of Interest}

The authors declare that a grant, scholarship, and/or funding does not lead to any conflicts of interest. Additionally, the authors declare that there are no conflicts of interest regarding the publication of this manuscript.

\section{References}

[1] fib (International Federation for Structural Concrete), Guidelines for the design of footbridges, fib Bulletin 32, Lausanne, Switzerland, 2005.

[2] V. Gribniak, G. Kaklauskas, D. Cygas, D. Bacinskas, R. Kupliauskas, and A. Sokolov, "Investigation of concrete cracking effect in deck slab of continuous bridges," Baltic Journal of Road and Bridge Engineering, vol. 5, no. 2, pp. 83-88, 2010.

[3] J. Strasky, Stress Ribbon and Cable-Supported Pedestrian Bridges (Structures and Buildings), ICE Publishing, 2nd edition, 2011.

[4] A. Juozapaitis, T. Merkevičius, A. Daniūnas, R. Kliukas, G. Sandovič, and O. Lukoševičienè, "Analysis of innovative twospan suspension bridges," Baltic Journal of Road and Bridge Engineering, vol. 10, no. 3, pp. 269-275, 2015.

[5] A. K. Arnautov, V. Kulakov, J. Andersons, V. Gribniak, and A. Juozapaitis, "Experimental investigation on stiffness and strength of single-lap z-pinned joints in a laminated CFRP stress-ribbon strip," The Baltic Journal of Road and Bridge Engineering, vol. 11, no. 2, pp. 120-126, 2016.

[6] K.-J. Han, N.-H. Lim, M.-G. Ko, and K.-D. Kim, "Efficient assumption of design variables for stress ribbon footbridges," KSCE Journal of Civil Engineering, vol. 20, no. 1, pp. 250-260, 2016.

[7] A. Goldack, M. Schlaich, and M. Meiselbach, "Stress ribbon bridges: mechanics of the stress ribbon on the saddle," ASCE 
Journal of Bridge Engineering, vol. 21, no. 5, Article ID 04015089, 2016.

[8] J. Soria, I. M. Díaz, J. H. García-Palacios, and N. Ibán, "Vibration monitoring of a steel-plated stress-ribbon footbridge: uncertainties in the modal estimation," ASCE Journal of Bridge Engineering, vol. 21, no. 8, article C5015002, 2016.

[9] A. Juozapaitis, P. Vainiūnas, and G. Kaklauskas, "A new steel structural system of a suspension pedestrian bridge," Journal of Constructional Steel Research, vol. 62, no. 12, pp. 1257-1263, 2006.

[10] G. Sandovič, A. Juozapaitis, and R. Kliukas, "Simplified engineering method of suspension two-span pedestrian steel bridges with flexible and rigid cables under action of asymmetrical loads," The Baltic Journal of Road and Bridge Engineering, vol. 6, no. 4, pp. 267-273, 2011.

[11] H. T. Thai and D. H. Choi, "Advanced analysis of multi-span suspension bridges," Journal of Constructional Steel Research, vol. 90, pp. 29-41, 2013.

[12] R. Karoumi, "Some modeling aspects in the nonlinear finite element analysis of cable supported bridges," Computers \& Structures, vol. 71, no. 4, pp. 397-412, 1999.

[13] M. Lepidi and V. Gattulli, "Non-linear interactions in the flexible multi-body dynamics of cable-supported bridge crosssections," International Journal of Non-Linear Mechanics, vol. 80, pp. 14-28, 2016.

[14] T. Kulbach, "Stress-ribbon bridges stiffened by arches or cables," in Proceedings of the 2nd International PhD Symposium in Civil Engineering, pp. 338-345, Budapest, Hungary, 1998.

[15] J. Radnić, D. Matešan, and D. Buklijaš-Kobojević, "Numerical model for analysis of stress-ribbon bridges," Građevinar, vol. 67, no. 10, pp. 959-973, 2015.

[16] M. Schlaich and A. Bleicher, "Clamping tape bridge with carbon fiber lamellae,” Bautechnik, vol. 84, no. 5, pp. 311-319, 2007.

[17] C. Petersen, Stahlbau, Publisher Vieweg and son, Braunschweig / Wiesbaden, 1988.

[18] S. Palkowski, Statics of Rope Constructions, Springer Publishing House, 1990.

[19] F. Otto, Shape, Edition Axel Menges, 2001. 


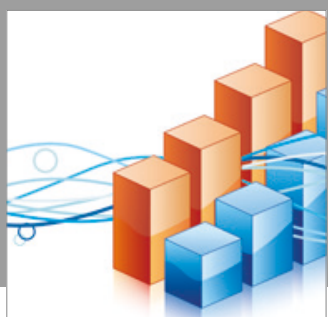

Advances in

Operations Research

vatersals

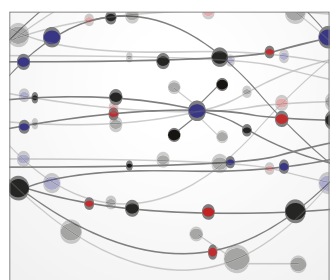

\section{The Scientific} World Journal
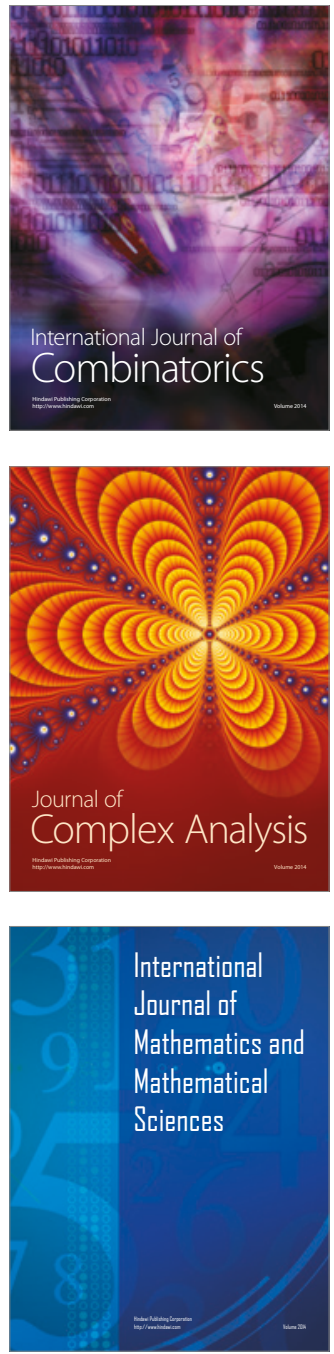
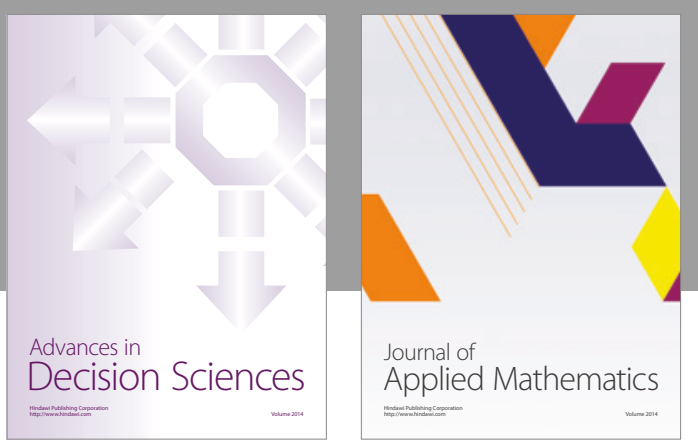

Algebra

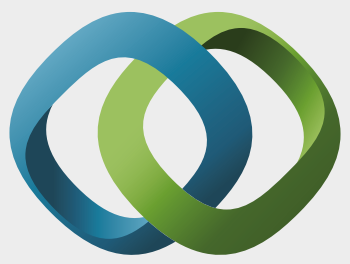

\section{Hindawi}

Submit your manuscripts at

https://www.hindawi.com
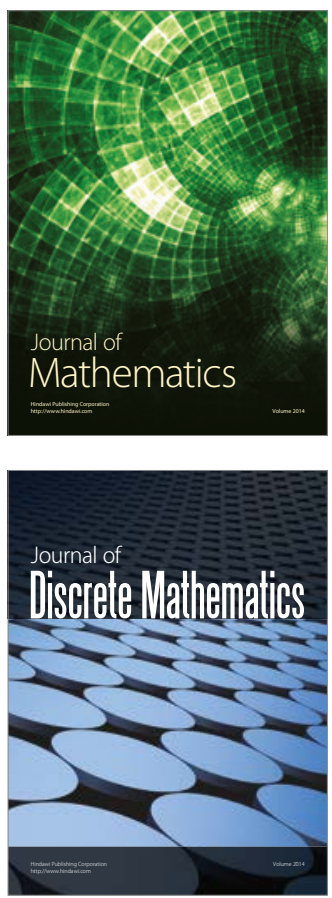

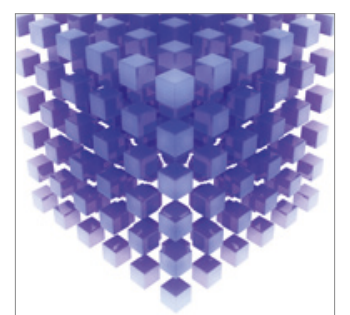

Mathematical Problems in Engineering
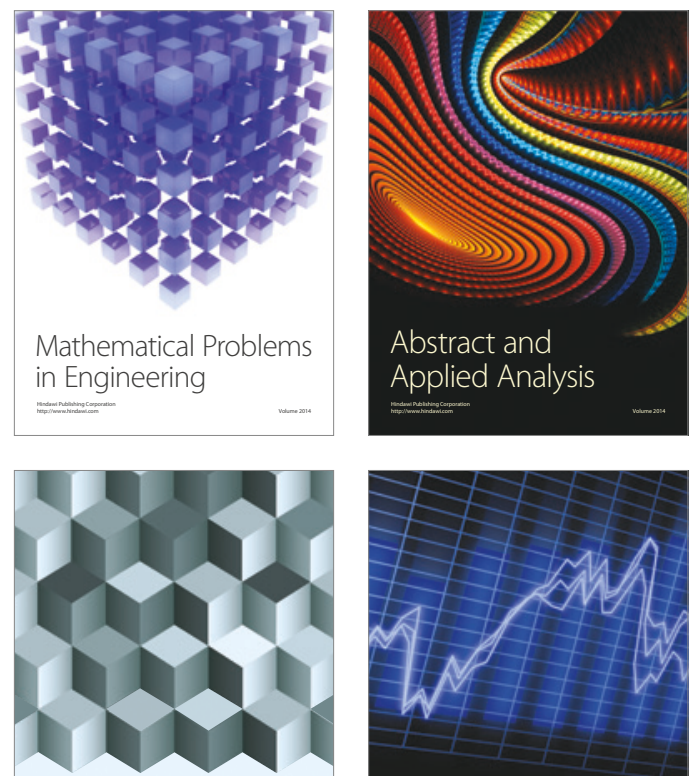

Journal of

Function Spaces

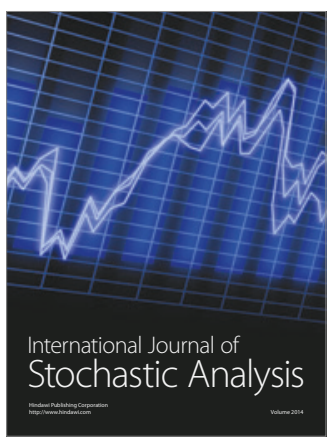

Probability and Statistics
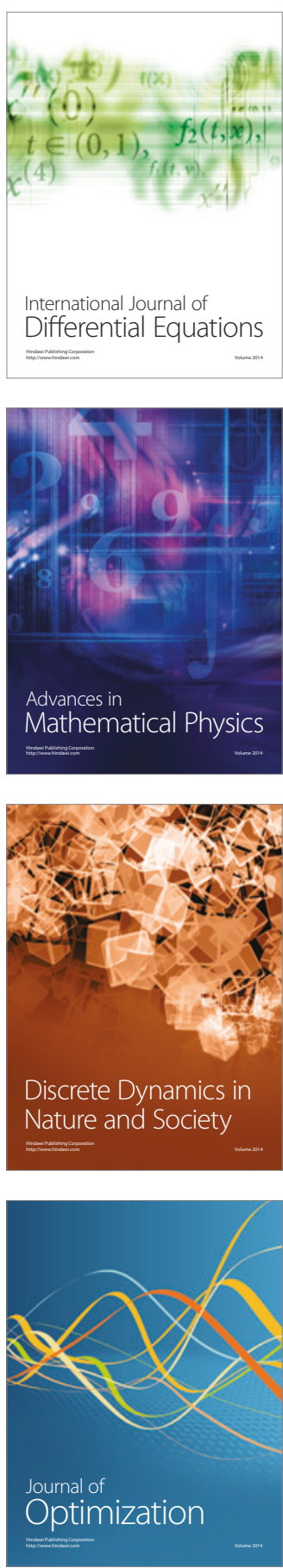